Part of Journal of Research of the National Bureau of Standards, Volume 21, September 1938

\title{
RELATION OF COMPOSITIONS AND HEATS OF SOLU- TION OF PORTLAND CEMENT CLINKER
}

\author{
By Herbert Insley, Einar P. Flint, Edwin S. Newman, and J. Arthur Swenson
}

\section{ABSTRACT}

The results of chemical and microscopic analyses and heat-of-solution measurements on samples of commercial portland cement clinker are reported. Differences between quantitative microscopic analysis and compound composition calculated from chemical analysis have systematic relationships with chemical composition of the clinker. The heats of solution calculated from compound composition by microscopic and by chemical analysis show fair correspondence with the observed heats of solution. Assumptions on which both methods of calculation are based are shown to be somewhat faulty.

\section{CONTENTS}

I. Introduction Page

II. Materials

III. Methods and apparatus

1. Preparation of samples

2. Chemical analysis

3. Microscopic examination

4. Heat of solution

IV. Results

1. Quantitative determinations

2. Qualitative microscopic examination _ $\ldots \ldots \ldots 59$

(a) $3 \mathrm{CaO} . \mathrm{SiO}_{2} \ldots$

(b) $2 \mathrm{CaO} . \mathrm{SiO}_{2}$

(c) "Light interstitial" material

(d) "Dark interstitial" material

(e) Free $\mathrm{MgO}_{\ldots} \ldots \ldots$

(f) Free $\mathrm{CaO}$

V. Discussion_.._.

VI. Summary

VII. References

\section{INTRODUCTION}

It has long been recognized [1] ${ }^{1}$ that many of the properties of concrete are dependent in part on the relative proportions of the compounds which are present. Determinations of the contributions of individual compounds to the properties of cements and concretes $[2,3]$ have been based on the assumptions of previous investigators that the cement clinker is completely crystalline and that no more than six phases-3CaO. $\mathrm{SiO}_{2}, 2 \mathrm{CaO} . \mathrm{SiO}_{2}, \quad 3 \mathrm{CaO} . \mathrm{Al}_{2} \mathrm{O}_{3}, 4 \mathrm{CaO} \cdot \mathrm{Al}_{2} \mathrm{O}_{3}$. $\mathrm{Fe}_{2} \mathrm{O}_{3}$, free $\mathrm{CaO}$, and free $\mathrm{MgO}$ (periclase) - are present.

\footnotetext{
${ }^{1}$ Figures in brackets indicate the literature references at the end of this paper.
} 
The accuracy of such methods depended in large part on the validity of these two assumptions. The recent development of a method for the microscopic examination of polished and etched specimens of portland cement clinker using reflected light $[4,5]$ permits ready distinction of the constituents and precise determination of the boundaries of individual crystals. The combination of this method with one for measuring the relative amounts of the different constituents makes possible a quantitative and qualitative comparison of the phases actually present in the clinker with those calculated from the chemical analyses.

It is the purpose of the present paper to make such comparisons for a series of commercial cement-clinker samples ${ }^{2}$ and to compare the heats of solution obtained by calculation from both microscopic measurement and chemical analysis with the experimentally determined heats of solution.

\section{MATERIALS}

Twenty-six different samples of clinker were available for this study from five different sources. These included ten samples of "modified low-heat" (type B) clinkers representative of nine brands of cement used in dam construction by the Tennessee Valley Authority (designated by index letter $T$ ), three samples of clinker representative of "modified low-heat" cements used in the construction of the Tygart River Dam, West Virginia (designated with index letter W), and two samples of clinker representative of "low-heat" cements used in the construction of Boulder Dam (index letter B). A fourth source was a group of 50 samples of clinker obtained through the generous cooperation of Dalton G. Miller, senior drainage engineer, U. S. Department of Agriculture (index letter M). Ten samples showing wide variations in composition were chosen from this group after a study of the analyses of the corresponding cements. A single sample obtained from the manufacturer (index letter $\mathrm{P}$ ) is listed because its $\mathrm{Al}_{2} \mathrm{O}_{3}$ and $\mathrm{Fe}_{2} \mathrm{O}_{3}$ content is low and its $\mathrm{CaO}$ content high.

The pure compounds used for the determination of heat of solution were obtained from several sources. Tricalcium aluminate and $4 \mathrm{CaO} \cdot \mathrm{Al}_{2} \mathrm{O}_{3} \cdot \mathrm{Fe}_{2} \mathrm{O}_{3}$, which were procured from William Lerch, were examined microscopically and found to be essentially homogeneous. Samples of $\mathrm{CaO}$ and $\mathrm{MgO}$ were obtained by heating the chemically pure carbonates at about $1,400^{\circ} \mathrm{C}$ and $\beta 2 \mathrm{CaO} . \mathrm{SiO}_{2}$ was made by heating $\mathrm{CaCO}_{3}$ and $\mathrm{SiO}_{2}$ in the proper proportions together with an amount of $\mathrm{H}_{3} \mathrm{BO}_{3}$ sufficient to give 0.2 percent of $\mathrm{B}_{2} \mathrm{O}_{3}$ in the final product.

\section{METHODS AND APPARATUS}

\section{PREPARATION OF SAMPLES}

The samples of commercial clinker weighed from 1 to $2 \mathrm{~kg}$. About one-third of each sample was so crushed as to avoid the production of a large amount of fine material and then sieved. The material passing: a No. 4 and retained on a No. 14 sieve was used for the experiments, one portion being reserved for chemical analysis, another for microscopic examination and a third for heat-of-solution measurements.

\footnotetext{
${ }^{2}$ Some preliminary quantitative results on a small number of clinker samples were given in a paper by Swenson and Flint [6].
} 


\section{CHEMICAL ANALYSIS}

The usual methods of quantitative analysis were used for all determinations except those of the alkalies, in which case the J. Lawrence Smith method of decomposition was followed by the determination of $\mathrm{Na}_{2} \mathrm{O}$ by precipitation as sodium zinc uranyl acetate and of $\mathrm{K}_{2} \mathrm{O}$ as potassium chloroplatinate. Free $\mathrm{CaO}$ was determined by the ammonium-acetate method [7].

\section{MICROSCOPIC EXAMINATION}

For examination in polished etched preparations by reflected light the crushed clinker sample was placed in a shell vial of about $1.5 \mathrm{~cm}$ inside diameter and immersed in Bakelite BR 0014 liquid resinoid. The preparation was evacuated in a vacuum desiccator by means of a faucet aspirator for 2 or 3 hours and then heated in an oven at about $80^{\circ} \mathrm{C}$ for about 15 hours. The temperature was then raised to $100^{\circ} \mathrm{C}$ and the heating continued about 7 hours or until the Bakelite was thoroughly hardened. After breaking the vial away, the lower surface of the preparation was ground down with No. 150 silicon carbide and water on a rotating lap until the clinker grains were exposed. Final grinding was done by hand with emery and alcohol on a slab of plate glass. The specimen was carefully washed with alcohol and polished with rouge and alcohol on a canvas-covered disk rotating at about 1,200 rpm. The polished sections were examined with a vertical illuminator [5].

A Wentworth recording micrometer [8] was used for quantitative microscopic analysis. This instrument has five micrometer screws, each one of which moves the specimen independently across the field beneath the reference cross hair in the eyepiece. The micrometer screw assigned to a particular constituent (phase) in the clinker is used for traversing grains of that constituent. The readings on the micrometer heads at the end of a complete traverse record the total linear intercepts for the different constituents. A series of traverses were made on each specimen, consecutive traverses being spaced at constant intervals. The specimens were of such a size that 11 traverses, $1 \mathrm{~mm}$ apart, could be made. Assuming uniform distribution of constituents of sufficiently small grain size, the ratios of the linear intercepts of the constituents are equal to the vclumetric ratios of the constituents in the specimen. The average of the micrometer readings on five different preparations was taken for the analysis of each sample brand. The average deviations from the mean were less than \pm 2 percent for most samples. In recalculating volume percentages to weight percentages, the density values were as follows: $\beta 2 \mathrm{CaO} . \mathrm{SiO}_{2}$, 3.28 [9] ; $3 \mathrm{CaO} . \mathrm{SiO}_{2}, 3.13[10] ; 4 \mathrm{CaO} . \mathrm{Al}_{2} \mathrm{O}_{3} . \mathrm{Fe}_{2} \mathrm{O}_{3}, 3.77$ [10]. Because the composition of the glass phase is variable and indeterminable, a value of 3.00 for the density of $3 \mathrm{CaO} \cdot \mathrm{Al}_{2} \mathrm{O}_{3}$, found by averaging two previously determined values $[10,11]$ was used for the total "dark interstitial" material.

The preparations were first etched with water for 2 seconds, immediately rinsed with alcohol and dried. This etching served to distinguish free $\mathrm{MgO}$, free $\mathrm{CaO}$, and crystalline "dark interstitial" material [12] from the rest of the clinker constituents. After quantitative microscopic analysis for these three constituents, the preparation was etched for 3 seconds in a 1-percent alcoholic solution of $\mathrm{HNO}_{3}$ to 
differentiate $2 \mathrm{CaO} . \mathrm{SiO}_{2}, 3 \mathrm{CaO} \cdot \mathrm{SiO}_{2}, 4 \mathrm{CaO} \cdot \mathrm{Al}_{2} \mathrm{O}_{3} \cdot \mathrm{Fe}_{2} \mathrm{O}_{3}$, and total "dark interstitial" material.

As a part of the qualitative examination, all samples were examined petrographically mounted as powders in liquids of known refractive index. Thin sections and polished thin sections [12] were also made of a few samples.

\section{HEAT OF SOLUTION}

The heats of solution of the clinker samples and of the pure compounds were determined at $25^{\circ} \mathrm{C}$ with an isothermal calorimeter previously described [13, 14], in a solvent consisting of a mixture of $648.5 \mathrm{~g}$ of $2.500 \pm 0.002 \mathrm{~N} \mathrm{HNO}_{3}$ and $11.5 \mathrm{~g}$ of reagent quality HF (48 percent). All experimental heats of solution were calculated on an ignition-loss-free basis. The values of the heats of solution of the pure compounds which were used in the computation of the heats of solution of the clinkers as derived from chemical and microscopic analysis are given in table 1. Differences between these values and those given by Lerch and Brownmiller [15] for the same compounds may be attributed to differences in calorimeters and to volumes and concentrations of the solvents used. In calculating the heat of solution of glass, a value of $700 \mathrm{cal} / \mathrm{g}$ was used. This value represents an approximate mean of the values reported by Lerch and Brownmiller [15] for glasses with the same range in $\mathrm{Al}_{2} \mathrm{O}_{3} / \mathrm{Fe}_{2} \mathrm{O}_{3}$ ratios as the clinker samples in the present paper.

TABLE 1.-Heats of solution of pure compounds

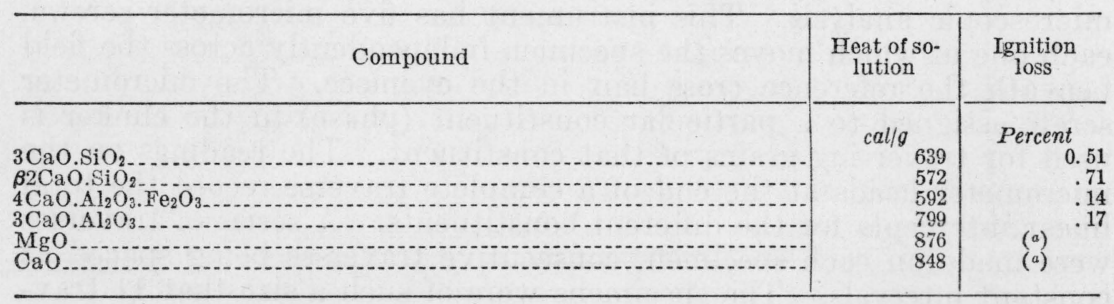

a $\mathrm{MgO}$ and $\mathrm{CaO}$ were freshly ignited.

\section{RESULTS}

\section{QUANTITATIVE DETERMINATIONS}

The results of chemical analysis, quantitative microscopic analysis and heat-of-solution determinations are given in table 2 . In order to facilitate comparison of results, the values for corresponding constituents as found by calculation of the compound composition according to the Bogue method $[16,17]$ and by microscopic analysis are given in adjacent columns. The designations $\mathrm{C}_{3} \mathrm{~S}\left(3 \mathrm{CaO} . \mathrm{SiO}_{2}\right)$ and $\mathrm{C}_{2} \mathrm{~S}\left(2 \mathrm{CaO}^{-\mathrm{SiO}_{2}}\right)$ are used for both calculated compound composition and microscopic analysis. The constituent designated "light interstitial" by microscopic analysis is considered equivalent to $\mathrm{C}_{4} \mathrm{AF}$ $\left(4 \mathrm{CaO} \cdot \mathrm{Al}_{2} \mathrm{O}_{3} \cdot \mathrm{Fe}_{2} \mathrm{O}_{3}\right)$ by calculation, and the constituent designated "total dark interstitial" by microscopic analysis is considered the nearest equivalent to $\mathrm{C}_{3} \mathrm{~A}\left(3 \mathrm{CaO} \cdot \mathrm{Al}_{2} \mathrm{O}_{3}\right)$ by calculation. The values given in the column headed "crystalline dark interstitial" are for 
TABLE 2.-Compositions and heats of solution of commercial clinker samples

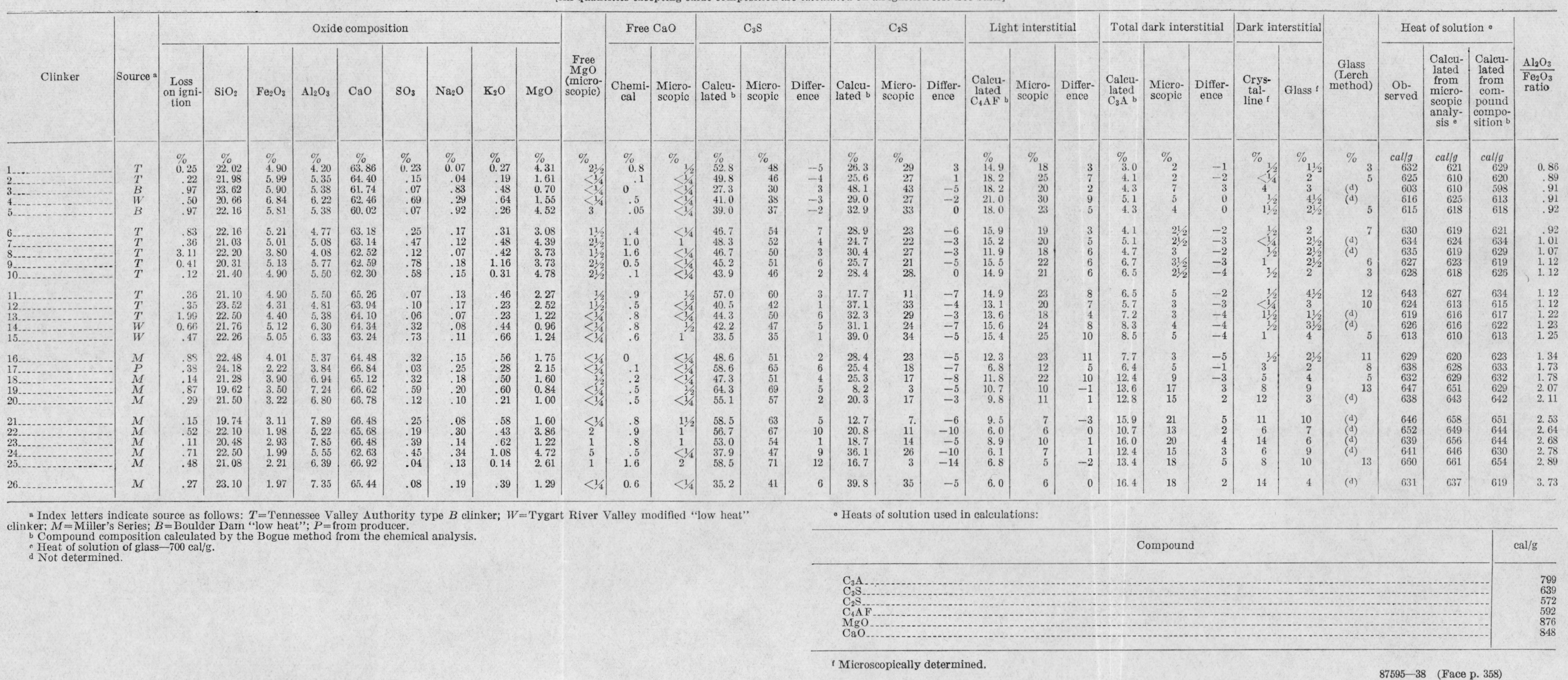


material rapidly etched by $\mathrm{H}_{2} \mathrm{O}$ and determined microscopically. The difference between that value and the value found under the heading, "total dark interstitial", is recorded in the column under "dark interstitial-glass." Determinations of glass by the heat-ofsolution method [15] were made on several samples by William Lerch. These are recorded in the column designated "Glass-Lerch Method."

\section{QUALITATIVE MICROSCOPIC EXAMINATION}

No attempt will be made in the following record of the qualitative microscopic examinations to give detailed results on each brand of clinker, because the structural and optical variations of most of the constituents in individual samples do not at present have a recognizable relation to the chemical composition or to the heats of solution.

(a) $3 \mathrm{CaO} . \mathrm{SiO}_{2}$

The samples examined show a wide range in size and perfection of outer form of the tricalcium silicate crystals. The crystals of this compound are on the average larger than those of any other compound, but the variation in size is large, not only from one lot of clinker to another, but from one piece of clinker to another. The crystals in some samples show considerable perfection of form, the individuals in polished section having straight edges and sharp angles. In other samples there is marked corrosion with rounding of angles and deep embayment of edges. A tabulation of the observations made on the whole set of samples indicates that the tricalcium silicate crystals in samples with low $\mathrm{Al}_{2} \mathrm{O}_{3} / \mathrm{Fe}_{2} \mathrm{O}_{3}$ ratios have greater perfection of form, whereas the crystals in samples with high $\mathrm{Al}_{2} \mathrm{O}_{3} / \mathrm{Fe}_{2} \mathrm{O}_{3}$ ratios are deeply corroded and embayed. The corroded crystals are generally, although not always, surrounded by a fringe of minute crystals of $2 \mathrm{CaO} . \mathrm{SiO}_{2}$ (see p. 360 ).

The existence of zoning in $3 \mathrm{CaO} . \mathrm{SiO}_{2}$, and its relation to solid solution, have been noted in a previous publication [5]. Some degree of zoning is present in all the samples studied in the present investigation, although in several cases it can be observed only under the most favorable etching conditions. ${ }^{3}$ The most pronounced zoning was observed in tricalcium silicate crystals in samples 10,23 , and 26 , whereas samples $6,8,11,12$, and 16 exhibited very little zoning. The zone boundaries generally parallel the crystal edges, although infrequently the boundaries appear to be curved or irregular. Rhythmic zoning is not unusual, weakly etched alternating with strongly etched zones. The degree of etching and the development of the zoning are affected considerably by the orientation of the crystals. Surfaces parallel to basal faces etch weakly and show no zoning, whereas surfaces normal to basal faces etch most strongly and show the greatest development of zoning. No close relation between the zoning of $3 \mathrm{CaO} . \mathrm{SiO}_{2}$ and the composition of the clinker has yet been found.

Solid solution in $3 \mathrm{CaO} . \mathrm{SiO}_{2}$ crystals is shown by other optical evidence as well as zoning. Samples which contain crystals that show strong zonal etching are also found to contain crystals with marked zonal extinction when examined petrographically. A change

${ }_{3}$ The most satisfactory etching conditions to produce evidence of zoning were 3 seconds at $25^{\circ} \mathrm{C}$ in a solution of 1 percent of $\mathrm{HNO}_{3}$ in alcohol. 
in index of refraction from interior to exterior of such crystals or from a strongly zoned to an unzoned crystal is, however, not detectable.

\section{(b) $2 \mathrm{CaO} . \mathrm{SiO}_{2}$}

All dicalcium silicate in industrial clinker is believed to be of the beta form. Three types of $\beta 2 \mathrm{CaO} \cdot \mathrm{SiO}_{2}$ differing somewhat in twinning and in habit have been distinguished. These were named types I, II, and III in a previous paper [5]. Another variant has been observed in many clinker specimens in the present investigation. It is called type Ia and is distinguished from type I by the presence of discrete particles along what are apparently traces of twinning planes (figs. 1 and 2). This structure is believed to be caused, according to Tavasci's theory [4], by unmixing during cooling of a material in solid solution in $2 \mathrm{CaO} . \mathrm{SiO}_{2}$.

Examples of all four types have been found in the clinker specimens studied. Type II, containing a single set of parallel twinning lamellae, occurs only in samples 4 and 15 . Type III, often containing irregular cracks or veinlets but without distinctive twinning lamellae, occurs sometimes as overgrowths on crystals of types I and Ia and sometimes as individual crystals. Types I and Ia are sometimes found in the same clinker piece. Crystals of type I are more abundant than those of any other type in the majority of the samples. All of the dicalcium silicate crystals studied exhibit rounded or serrated edges with no evidence of regular external form.

In many of the specimens, crystals of $3 \mathrm{CaO} . \mathrm{SiO}_{2}$ are surrounded by a fringe of minute rounded particles (figs. 3 and 4). Although these particles are generally too small to show the characteristic internal structure with the microscope, their etching behavior indicates that they are $2 \mathrm{CaO} \cdot \mathrm{SiO}_{2}$. This fringing material generally surrounds $3 \mathrm{CaO} \cdot \mathrm{SiO}_{2}$ crystals exhibiting considerable corrosion and embayment and, therefore, it has been found in this investigation in samples with the higher $\mathrm{Al}_{2} \mathrm{O}_{3} / \mathrm{Fe}_{2} \mathrm{O}_{3}$ ratios. The other types of $2 \mathrm{CaO}$. $\mathrm{SiO}_{2}$ apparently bear no relation to the chemical composition of the clinker samples.

Crystals of dicalcium silicate show a wide range in size, but are in general smaller than those of the tricalcium silicate.

\section{(c) "LIGHT INTERSTITIAL" MATERIAL}

In the investigation of cement clinker by means of the reflecting microscope, two types of interstitial material have been differentiated which have been called, because of their relative reflectivity and reaction to etchants, the "light interstitial" material and the "dark interstitial" material [12]. The evidence previously gathered and supported by the results of the present investigation indicates that the light interstitial material is crystalline with optical properties like those of $4 \mathrm{CaO} \cdot \mathrm{Al}_{2} \mathrm{O}_{3} \cdot \mathrm{Fe}_{2} \mathrm{O}_{3}$. The light interstitial material is intimately associated with the dark interstitial in most of the clinker specimens. Not only the size of the aggregates but the size of the individual crystals appears to bear some relation to the chemical composition, those clinker samples with the lower $\mathrm{Al}_{2} \mathrm{O}_{3} / \mathrm{Fe}_{2} \mathrm{O}_{3}$ ratios generally containing the larger crystals of $4 \mathrm{CaO} \cdot \mathrm{Al}_{2} \mathrm{O}_{3} \cdot \mathrm{Fe}_{2} \mathrm{O}_{3}$. The form of the crystals is also somewhat dependent on chemical composition. When the $\mathrm{Al}_{2} \mathrm{O}_{3} / \mathrm{Fe}_{2} \mathrm{O}_{3}$ is low, the crystals of $4 \mathrm{CaO} \cdot \mathrm{Al}_{2} \mathrm{O}_{3} \cdot \mathrm{Fe}_{2} \mathrm{O}_{3}$ 


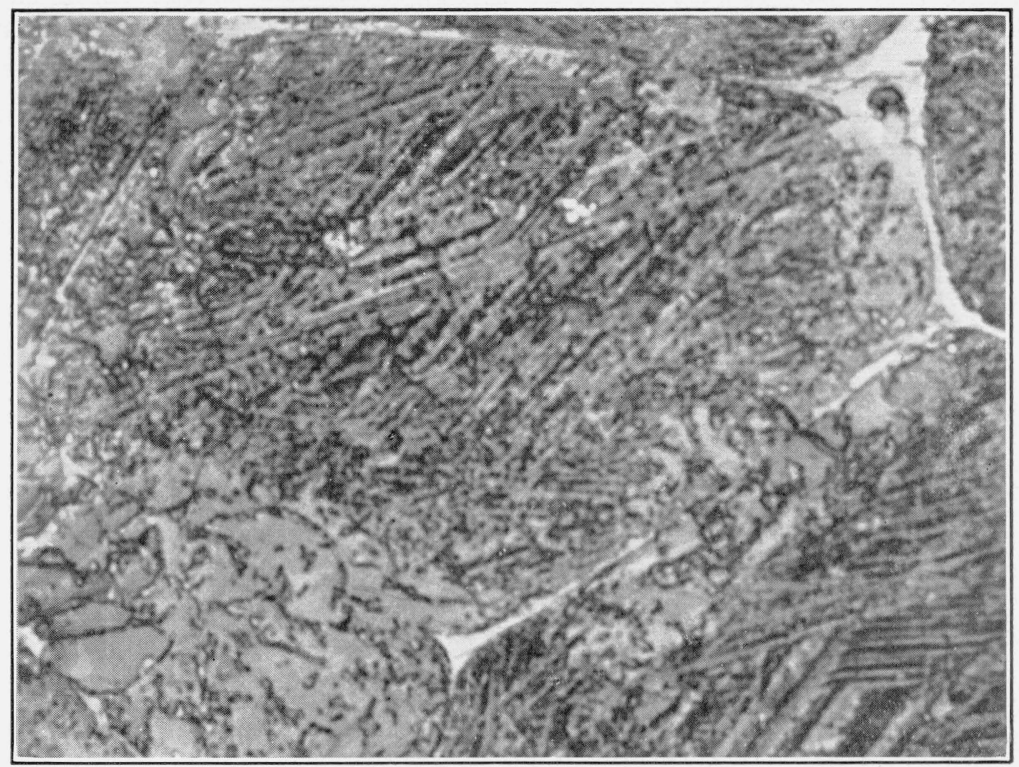

Figure 1.-2 $\mathrm{CaO} . \mathrm{SiO}_{2}$ of types $\mathrm{Ia}$ and III in clinker sample 17.

Etched with 1-percent alcoholic solution of $\mathrm{HNO}_{3}$. Reflected light. Magnification, $\times 1000$.

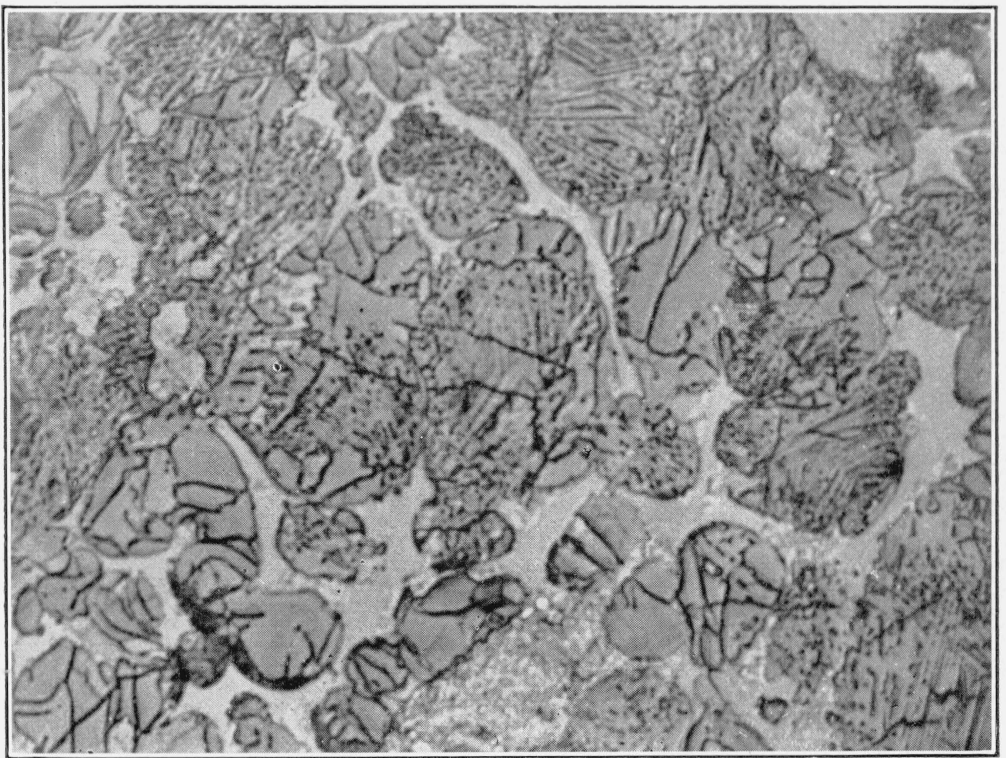

Figure 2.-2CaO. $\mathrm{SiO}_{2}$ of types Ia and III in clinker sample 26. Etched with 1-percent alcoholic solution of $\mathrm{HNO}_{3}$. Reflected light. Magnification, $\times 500$. 


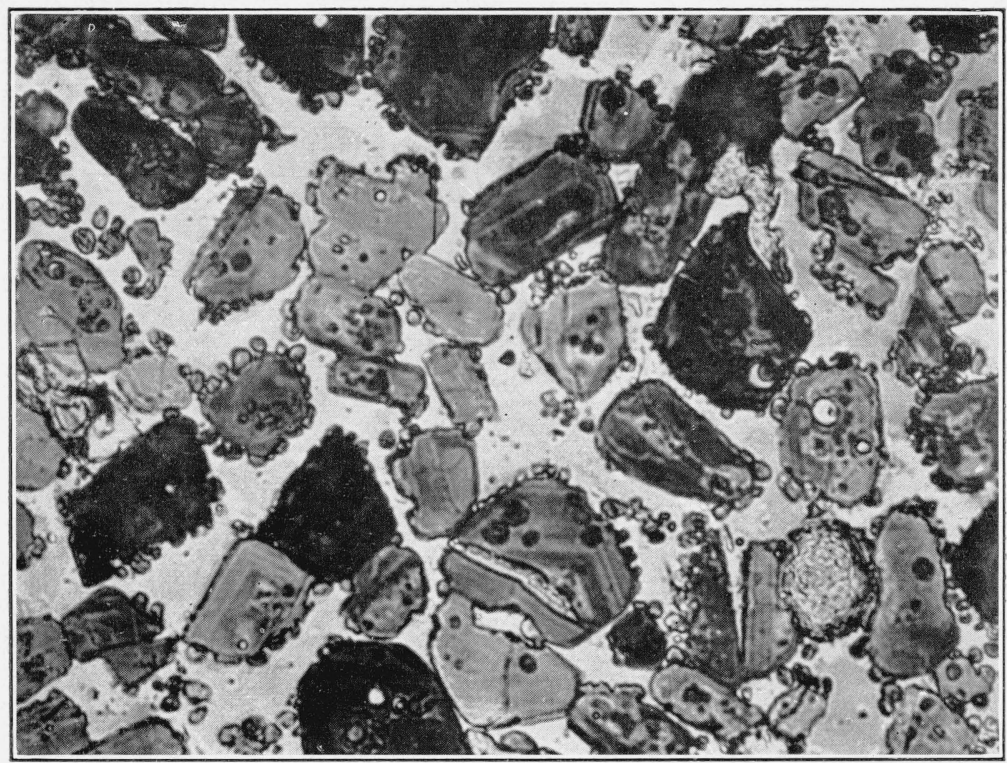

FIGURE 3.-Corroded crystals of $3 \mathrm{CaO} . \mathrm{SiO}_{2}$ fringed with unusually large, rounded grains of $2 \mathrm{CaO} . \mathrm{SiO}_{2}$

From clinker sample 21. Etched with 1-percent alcoholic solution of $\mathrm{HNO}_{3}$. Reflected light. Magnification, $\times 500$.

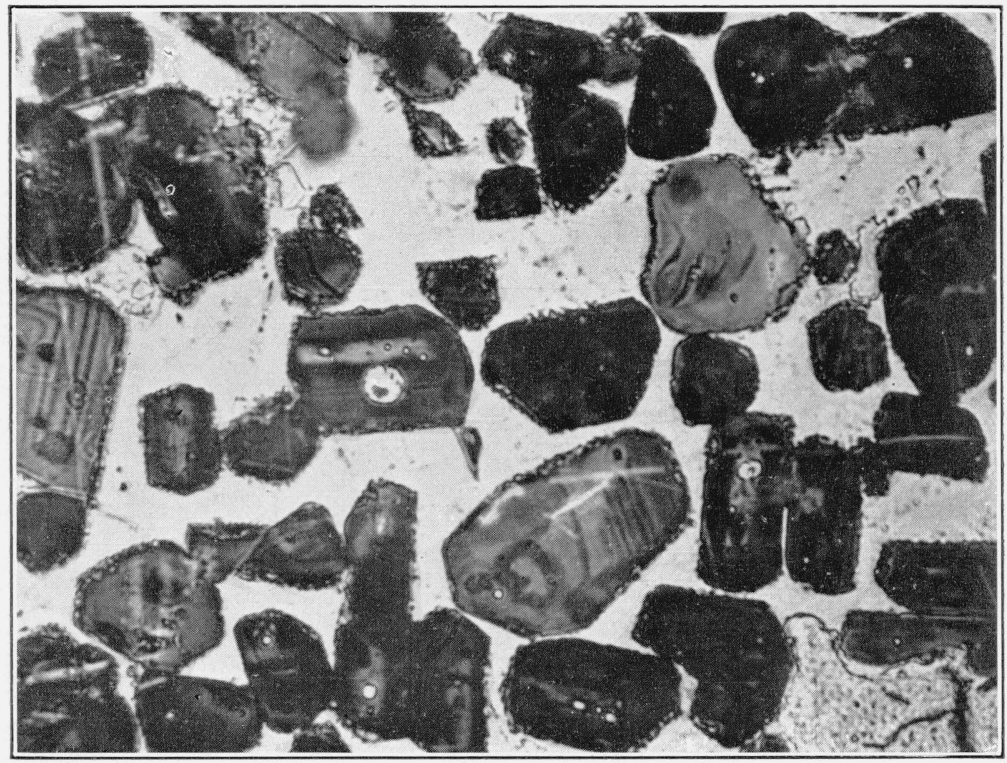

FIGURE 4.-Corroded crystals of $3 \mathrm{CaO} . \mathrm{SiO}_{2}$ fringed with rounded grains of $2 \mathrm{CaO} . \mathrm{SiO}_{2}$ of normal size.

From clinker sample 21. Etched with 1-percent alcoholic solution of $\mathrm{HNO}_{3}$. Reflected light. Magnification, $\times 500$. 
have good prismatic development with straight edges, but when the $\mathrm{Al}_{2} \mathrm{O}_{3} / \mathrm{Fe}_{2} \mathrm{O}_{3}$ ratio is high the faces are poorly developed, probably because they form at a later stage of the crystallization of the clinker.

Most of the $4 \mathrm{CaO} \cdot \mathrm{Al}_{2} \mathrm{O}_{3} \cdot \mathrm{Fe}_{2} \mathrm{O}_{3}$ crystals found in commercial cement clinker are pleochroic, but the pleochroism varies widely from one clinker sample to another and even from one crystal to another in the same sample. This variation appears to have no relation to the chemical composition of the sample. In one sample examined (No. 4) the larger crystals were light amber in color with no perceptible pleochroism, whereas the smaller crystals in the same clinker piece were much darker and exhibited strong pleochroism.

\section{(d) "DARK INTERSTITIAL" MATERIAL}

The dark interstitial material has been classified into crystalline and glassy types. One method of distinction is the rate of reaction with water when used as an etching reagent, the former type being rapidly etched and the latter slowly etched. ${ }^{4}$ The crystalline dark interstitial material can be subdivided into a rectangular isotropic form and a prismatic anisotropic form, whereas the glassy type has a variable index of refraction and is apparently isotropic when observed in thin section or powdered form. ${ }^{5}$

In the samples investigated the rectangular crystalline form, which has the optical properties of $3 \mathrm{CaO} \cdot \mathrm{Al}_{2} \mathrm{O}_{3}$, is found in only two samples (20 and 21) and there in only very small amounts. The anisotropic prismatic form, which appears to be produced only in the presence of alkali [12], is a much more abundant constituent. It occurs to some extent in all the samples examined; in samples with low $\mathrm{Al}_{2} \mathrm{O}_{3} / \mathrm{Fe}_{2} \mathrm{O}_{3}$ ratios it is present in small amounts and in localized clusters of crystals as if it were the result of nonuniformity of the mix, whereas in other samples the prismatic crystals are distributed more uniformly.

The dark interstitial material which reacts slowly with water has been found to some extent in all the samples in this series. Although it is impossible to measure the indices of refraction of this phase accurately, those samples having low $\mathrm{Al}_{2} \mathrm{O}_{3} / \mathrm{Fe}_{2} \mathrm{O}_{3}$ ratios contain glass which is microscopically colorless with an index of refraction less than 1.72, whereas those with high $\mathrm{Al}_{2} \mathrm{O}_{3} / \mathrm{Fe}_{2} \mathrm{O}_{3}$ ratios contain glass with an index higher than 1.72 and with a green color. In all the samples the glassy phase is intimately mixed with the prismatic crystals of $4 \mathrm{CaO} \cdot \mathrm{Al}_{2} \mathrm{O}_{3} \cdot \mathrm{Fe}_{2} \mathrm{O}_{3}$.

\section{(e) FREE MgO}

Free $\mathrm{MgO}$ occurs as angular grains with the optical properties of periclase. These have been identified in polished sections of commercial clinker [12]. In the present investigation free $\mathrm{MgO}$ has. been seen in the majority of the samples. Although the magnesia grains are small, it is observed that, in general, the greater the amount of $\mathrm{MgO}$ the larger the grain size of the periclase. The free $\mathrm{MgO}$ is associated with the interstitial material in all the samples. In most of the samples the periclase grains are more or less uniformly dis-

\footnotetext{
4 After immersion in water for 1 to 2 seconds, the first type is etched noticeably while the second type shows no perceptible effect.

' Continuous homogeneous grains of this glassy form appear perfectly isotropic, although they are so. small that they may actually be slightly birefringent. Therefore, it is impossible to decide whether or not the glassy phase is equivalent to the "metastable phase" of Brownmiller [18].
} 
tributed throughout the specimens examined, but in some (notably No. 5) the grains occur in clusters. This may be the result of improper mixing of raw materials.

\section{(f) FREE $\mathrm{CaO}$}

Free $\mathrm{CaO}$ occurs as rounded grains which are detected by etching reactions previously described [12]. In most of the samples the free $\mathrm{CaO}$ grains are present as clusters associated with concentrations of $3 \mathrm{CaO} \cdot \mathrm{SiO}_{2}$ crystals and, therefore, are probably the result of some lack of uniformity in the batch.

\section{DISCUSSION}

A comparison of direct and indirect methods of quantitative determination of the phases present in portland cement clinker shows certain systematic relations (table 2). These are most apparent when the columns headed "difference" are examined. These columns show the differences between the values for equivalent constituents as determined microscopically and chemically. It will be observed that the percentages of $2 \mathrm{CaO} . \mathrm{SiO}_{2}$ determined microscopically exceed those determined chemically only for two samples with the lowest $\mathrm{Al}_{2} \mathrm{O}_{3}$ / $\mathrm{Fe}_{2} \mathrm{O}_{3}$ ratios, whereas the percentages of $3 \mathrm{CaO} . \mathrm{SiO}_{2}$ obtained microscopically are less than those obtained chemically only for samples with low $\mathrm{Al}_{2} \mathrm{O}_{3} / \mathrm{Fe}_{2} \mathrm{O}_{3}$ ratios. The microscopic values for "light interstitial" material tend to be greater than those for calculated $4 \mathrm{CaO} . \mathrm{Al}_{2} \mathrm{O}_{3} \cdot \mathrm{Fe}_{2} \mathrm{O}_{3}$ for samples with low $\mathrm{Al}_{2} \mathrm{O}_{3} / \mathrm{Fe}_{2} \mathrm{O}_{3}$ ratios, but the differences are close to zero for samples with $\mathrm{Al}_{2} \mathrm{O}_{3} / \mathrm{Fe}_{2} \mathrm{O}_{3}$ ratios of 2.00 or greater. The reverse is true when microscopically determined total "dark interstitial" material is compared with calculated $3 \mathrm{CaO} \cdot \mathrm{Al}_{2} \mathrm{O}_{3}$. The microscopic values are less than or equal to the calculated (with one exception) for low $\mathrm{Al}_{2} \mathrm{O}_{3} / \mathrm{Fe}_{2} \mathrm{O}_{3}$ ratios and greater than the calculated for ratios more than 2.00 .

Several reasons may be given for the differences between the compositions determined microscopically and those obtained by calculation. The fact that tricalcium silicate contains other material in solid solution would tend to make the observed amount greater than that obtained by calculation by the Bogue method [16] as pure $3 \mathrm{CaO} . \mathrm{SiO}_{2}$. Moreover, Lea and Parker [19] have shown from a consideration of the system $\mathrm{CaO}-\mathrm{Al}_{2} \mathrm{O}_{3}-\mathrm{Fe}_{2} \mathrm{O}_{3}-\mathrm{SiO}_{2}$ that cement clinkers with high $\mathrm{Al}_{2} \mathrm{O}_{3} / \mathrm{Fe}_{2} \mathrm{O}_{3}$ ratios contain greater amounts of $3 \mathrm{CaO} . \mathrm{SiO}_{2}$ and lesser amounts of $2 \mathrm{CaO} \cdot \mathrm{SiO}_{2}$ when crystallization is arrested during cooling than when complete equilibrium is attained.

Because there is partial solid solution between $4 \mathrm{CaO} \cdot \mathrm{Al}_{2} \mathrm{O}_{3} \cdot \mathrm{Fe}_{2} \mathrm{O}_{3}$ and $3 \mathrm{CaO} \cdot \mathrm{Al}_{2} \mathrm{O}_{3}$ in the system $\mathrm{CaO}-\mathrm{Al}_{2} \mathrm{O}_{3}-\mathrm{Fe}_{2} \mathrm{O}_{3}$ [20], it seems probable that the excess of observed light interstitial material over calculated $4 \mathrm{CaO} . \mathrm{Al}_{2} \mathrm{O}_{3} \cdot \mathrm{Fe}_{2} \mathrm{O}_{3}$ in clinker with low $\mathrm{Al}_{2} \mathrm{O}_{3} / \mathrm{Fe}_{2} \mathrm{O}_{3}$ ratios may be explained by the earlier crystallization of $4 \mathrm{CaO} \cdot \mathrm{Al}_{2} \mathrm{O}_{3} \cdot \mathrm{Fe}_{2} \mathrm{O}_{3}$ with solid solution of material approximating $3 \mathrm{CaO} \cdot \mathrm{Al}_{2} \mathrm{O}_{3}$ in composition. In clinkers with high $\mathrm{Al}_{2} \mathrm{O}_{3} / \mathrm{Fe}_{2} \mathrm{O}_{3}$ ratios, dark interstitial material may be expected to crystallize first and to take some $4 \mathrm{CaO} \cdot \mathrm{Al}_{2} \mathrm{O}_{3} \cdot \mathrm{Fe}_{2} \mathrm{O}_{3}$ into solid solution. The prismatic doubly refracting constituents [12] presumably produced by alkalies are not accounted for in the Bogue method of calculation. Their presence would tend to increase the amount of dark interstitial material, but what the quantitative effect 
would be on the discrepancies between calculated and microscopically determined compositions is not known.

To account for the rather large differences between the light interstitial constituent and calculated $4 \mathrm{CaO} \cdot \mathrm{Al}_{2} \mathrm{O}_{3} \cdot \mathrm{Fe}_{2} \mathrm{O}_{3}$ in some samples, it has been suggested that the light interstitial constituent may consist of another phase besides $4 \mathrm{CaO} \cdot \mathrm{Al}_{2} \mathrm{O}_{3} \cdot \mathrm{Fe}_{2} \mathrm{O}_{3}$, for instance, a highly refractive iron-bearing glass which is not distinguished from $4 \mathrm{CaO}$.$\mathrm{Al}_{2} \mathrm{O}_{3} \cdot \mathrm{Fe}_{2} \mathrm{O}_{3}$ by the etching reagents used. Attempts to differentiate the light interstitial material into two phases by the use of other etching reagents and illuminating methods have thus far been unsuccessful.

In the $\mathrm{Bogue}$ method all the $\mathrm{MgO}$ is calculated as free $\mathrm{MgO}$ (periclase). In all but one of the samples examined the free $\mathrm{MgO}$ as determined by microscopic analysis is less than the total $\mathrm{MgO}$ by chemical analysis. Evidently a part of the $\mathrm{MgO}$ is dissolved in the glass or in one or more of the crystalline constituents.

The agreement between the microscopic method and the ammonium acetate method in the determination of free $\mathrm{CaO}$ is, in general, good. The somewhat lower results by the microscopic method for most samples are to be expected because the chemical method includes both free $\mathrm{Ca}(\mathrm{OH})_{2}$ and free $\mathrm{CaO}$, whereas the microscopic method distinguishes only crystalline $\mathrm{CaO}$. The large difference for sample 8 is probably to be attributed to a partial hydrolysis of the clinker constituents, as indicated by the high ignition loss.

Although the presence of glass is evidence that commercial clinkers are not the product of crystallization under equilibrium conditions, the simultaneous occurrence of fine-grained crystalline light and dark interstitial material with glass in the same specimen indicates also that the clinkers have not been completely quenched. The commercial product may, therefore, be considered as an intermediate stage between a material quenched from a definite temperature and one crystallized at continuous equilibrium conditions.

In comparing calculated and observed heats of solution (table 2) it is evident that, in general, the heats of solution as computed from calculated compound composition agree somewhat better with the observed than do those calculated from microscopic analysis, the average difference between observed and microscopic analysis being 8.3 cal/g and between observed and calculated compound composition being $5.6 \mathrm{cal} / \mathrm{g}$. In making the heat of solution calculations based upon the Bogue method of determining compound composition, it was assumed that:

1. The compounds calculated to be present had the compositions and the heats of solution of the pure compounds unaffected by solid solution.

2. The oxides present in minor amounts, such as alkalies, did not enter into compounds or affect the heats of solutions.

3. Perfect equilibrium crystallization took place during cooling without the formation of glass.

In making the calculation of heats of solution from microscopic analyses it was not only necessary to use the heats of solution of the pure compounds but also to use the heat of solution of $3 \mathrm{CaO} \cdot \mathrm{Al}_{2} \mathrm{O}_{3}$ for all the crystalline dark interstitial material, whether rectangular or prismatic. A constant value of $700 \mathrm{cal} / \mathrm{g}$ was used for all the glass, although the composition and consequently the heat of solution of 
the glass vary with the composition and rate of cooling of the clinker specimen.

All the assumptions made with respect to both types of calculation are known to be inexact, but they are felt to be the closest approximations that can be made at the present state of knowledge. Considering the errors in the basic assumptions, the degree of correspondence of either of the methods of calculations with the observed heats of solution has little significance.

The glass content by the Lerch method (table 2) is greater than the glass content by the microscopic method for all samples on which determinations were made. Because the Lerch method is essentially a heat-of-solution method it is open to some of the same errors (already pointed out by Lerch and Brownmiller [15]) that affect the calculation of heat of solution from compound compositions, namely, the ascumption that the compounds present are free from solid solution and the assumption that the alkalies and other minor oxides have no effect on the heat of solution. The accuracy of the method will be increased as more knowledge is obtained on the actual composition and properties of these compounds in cement clinker.

\section{SUMMARY}

The results of chemical and microscopic analysis and heat-ofsolution measurements on 26 samples of commercial portland cement clinker are reported.

A comparison of compound composition by microscopic analysis and by calculation from chemical analysis shows that:

1. The content of $3 \mathrm{CaO} \cdot \mathrm{SiO}_{2}$ by microscopic analysis is greater than by calculation, except for very low $\mathrm{Al}_{2} \mathrm{O}_{3} / \mathrm{Fe}_{2} \mathrm{O}_{3}$ ratios.

2. The content of $2 \mathrm{CaO} . \mathrm{SiO}_{2}$ is less by microscopic analysis, except for very low $\mathrm{Al}_{2} \mathrm{O}_{3} / \mathrm{Fe}_{2} \mathrm{O}_{3}$ ratios.

3. Microscopically determined "dark interstitial" material is less than calculated $3 \mathrm{CaO} . \mathrm{Al}_{2} \mathrm{O}_{3}$ for low $\mathrm{Al}_{2} \mathrm{O}_{3} / \mathrm{Fe}_{2} \mathrm{O}_{3}$ ratios and greater for high $\mathrm{Al}_{2} \mathrm{O}_{3} / \mathrm{Fe}_{2} \mathrm{O}_{3}$ ratios.

4. Microscopically determined "light interstitial" material is greater than calculated $4 \mathrm{CaO} \cdot \mathrm{Al}_{2} \mathrm{O}_{3} \cdot \mathrm{Fe}_{2} \mathrm{O}_{3}$ for low $\mathrm{Al}_{2} \mathrm{O}_{3} / \mathrm{Fe}_{2} \mathrm{O}_{3}$ ratios and approximately equal for high ratios.

Qualitative and quantitative microscopic analyses indicate that the crystalline compounds present are not pure, but contain limited amounts of material in solid solution.

Glass is present in all the samples studied.

A comparison of observed heats of solution with those calculated from chemical analysis and from microscopic analysis shows a fairly close correspondence, but it is pointed out that the assumptions on which the calculations by both methods are based are inexact.

The authors are indebted to Dalton G. Miller, senior drainage engineer, United States Department of Agriculture, for his kindness in obtaining samples of clinker from the manufacturers, to G. W. Ward, of the Portland Cement Association Fellowship at the National Bureau of Standards, for his many helpful suggestions, and especially to William Lerch, of the same organization, for generous cooperation in furnishing pure materials and in determining glass contents of many of the samples. 


\section{REFERENCES}

[1] P. H. Bates and A. A. Klein. Tech. Pap. BS 8 (1917) T78.

[2] Hubert Woods, H. H. Steinour and H. R. Starke. Ind. Eng. Chem. 24, 1207 (1932).

[3] Wm. Lerch and R. H. Bogue. BS J. Research 12, 645 (1934) RP684.

[4] B. Tavasci. Giorn. Chim. Ind. Applicata 16, 538 (1934).

[5] H. Inlsey. J. Research NBS 17, 353 (1936) RP917.

[6] J. A. Swenson and E. P. Flint, J. Research NBS 1\%, 261 (1936) RP910.

[7] Wm. Lerch and R. H. Bogue. Ind. Eng. Chem., Anal. Ed. 2, 296 (1930).

[8] C. K. Wentworth. J. Geol. 31, 228 (1923).

[9] A. L. Day and E. S. Shepherd. J. Am. Chem. Soc. 28, 1089 (1906).

[10] Wm. Lerch. Private communication.

[11] E. S. Shepherd and G. A. Rankin. Am. J. Sci. 28, 293 (1909).

[12] H. Insley and H. F. McMurdie. J. Research NBS 20, 173 (1938) RP1074.

[13] F. B. Hornibrook, G. L. Kalousek and C. H. Jumper. J. Research NBS 16, 487 (1936) RP887.

[14] E. S. Newman and L. S. Wells. J. Research NBS 20, 825 (1938) RP1107.

[15] Wm. Lerch and L. T. Brownmiller. J. Research NBS 18, 609 (1937) RP997.

[16] R. H. Bogue. Ind. Eng. Chem., Anal. Ed. 1, 192 (1929).

[17] L. A. Dahl, Rock Products 32, 23, 50 (1929).

[18] L. T. Brownmiller. Am. J. Sci. 35, 241 (1938).

[19] F. M. Lea and T. W. Parker. Bldg. Research Tech. Pap. No. 16, Dept. Sci. Ind. Research (England) (1935).

[20] H. F. McMurdie. J. Research NBS 18, 475 (1937) RP987.

Washington, July 28, 1938. 